\title{
Analysis of the Impact of Webcast on Consumers' Purchase Decision
}

\author{
ZiMu Zhang $^{1}$ \\ ${ }^{1}$ RDFZ Chaoyang Branch School, Beijing, China
}

\begin{abstract}
With the outbreak of the Internet celebrity economy, coupled with the rapid expansion of the live broadcast industry and technology, the new Internet economy has shown a diversified development pattern. This article has conducted an in-depth study of the impact of webcast on consumer purchasing decisions. The author believes that the goods brought by celebrities is a relatively new industry with potential for development. Especially in the post-epidemic era, the goods brought by celebrities on the Internet will be promoted by more and more brands and capital; but as an industry with only about ten years of development history. In the industry, the industry norms and guidelines are largely missing, and we can only find a few legal provisions to restrict it. As a sales model that is directly related to consumers, consumers, sellers and Internet celebrities should all be protected by corresponding laws. Despite the existence of irregular management, the intervention of the platform can make the three parties reach a certain degree of balance.
\end{abstract}

\section{INTRODUCTION}

Internet celebrities want to use social media to obtain fan traffic, they must ensure that they output valuable content. At the same time, live broadcasting also needs rich forms to meet the needs of viewers. People's use of fragmented time has also prompted the era of Internet celebrities to complete a variety of "Internet celebrities + " in the process of change. Among them, "Internet celebrities + live broadcast" has started from the initial fan rewards and brand promotion, and now uses live broadcast marketing to enable consumers to "watch while buying". The time period for consumers from understanding the product to completing the purchase behavior has been greatly shortened. With the help of live broadcast, Internet celebrities not only increase sales, but also enhance the interaction with fans, which affects fans' emotional attachment to online celebrities.

\section{LITERATURE REVIEW}

\section{A. Definition and classification of internet cerlebrities}

The emerging concept of Internet celebrities has been hotly discussed recently and has attracted great public attention. And 2010 is the time when China's real internet celebrity era is coming[1]. Due to the rapid development of the Internet and imitating the foreign Twitter model, Sina continued to ferment the benefits of Weibo in 2014. Numerous celebrities gather on Weibo, allowing people to pay attention to their lives and make the connection between people closer. And now the Internet celebrities we are talking about have also emerged. According to Sun Zhibing (2015), "Influencer" refers to a person who has become popular by netizens because of an event or behavior in reality or online life, or a person who has been popular for long-term continuous output of professional knowledge[2].

Internet celebrities are classified into multiple sections, among which self-media, e-commerce, and live broadcast are the mainstream orientations. Although there is no clear classification of Internet celebrities in academia, according to Ni Henghu (2018) and Baidu Baike (2019), the reasons for their fame can also be roughly divided into: First, they become famous because of their artistic talents, such as writers, Internet celebrities [3], southern schools Sanshu, Tang's third young master, etc. rely on his selfstudy under the control of his interest in a certain art and culture, thus forming his unique skills and fan group in a certain art field. Second, he is famous for being funny. Such Internet celebrities mainly display themselves in front of the audience, and their speech and behavior are mostly unexpected, so as to bring joy to the audience and attract target groups that need entertainment. Third, unexpected fame. Such Internet celebrities often become famous because of their own topicality and charm that attract the public, and they have not been actively hyped and displayed [4]. Therefore, such Internet celebrities often have shining points, and are highly concerned by the public's curiosity, such as the milk tea sister Zhang Zetian. Fourth, it became famous because of Internet celebrities. Such Internet celebrities often have capital and team backgrounds, and they can often enter the public eye with a higher quality and standard. Therefore, most of the Internet celebrities pushing hands need the team to support a large number of topics, so as to attract the 
attention of the public and attract the attention of netizens [5].

\section{B. Definbition and classification of webcast}

Webcasting is also a product of the rapid development of the Internet, which has strongly promoted and changed the way of disseminating video. Internet celebrities also regard live broadcasting as one of their powerful ways to increase popularity and achieve economic goals. Nowadays, the definition of webcast is not clear, but it is not difficult to understand literally, so Tan Chang (2018) proposed that webcast is provided by a webcaster without recording or recording, relying on the Internet and mobile phones or computers [6]. Live broadcast tools such as live broadcast on the web live broadcast platform, simultaneous live broadcast, multi-party display, and instant interaction with the audience through bullet screens or comments [7].

Lei Yuting (2017) classifies the diverse characteristics of webcasting into the following four categories. First, micro-live broadcast. The micro-live broadcast format, which was born in 2010, is a live broadcast format that users watch or live broadcast using mobile terminals such as mobile phones and tablet computers. The audience can watch real-time content for chat interaction or rewards, so that the flat interactivity of the live broadcast can be fully demonstrated. Second, social live streaming [8]. As the name suggests, social live broadcast is a form of live broadcast for social purposes. With the advancement of technology, remote interaction and social interaction have become more convenient, and social live broadcast is a powerful medium among them. And the use of YY, Huya and other social live broadcast software makes online social networking more intimate, and can also seek financial benefits for the host by giving gifts. Third, the game is broadcast live [9]. Game live broadcast is a live broadcast method with games as the main subject. Share the game process of the game anchor by sharing the game screen on live platforms such as Huya and Douyu. Many gamers who play the same game will learn technology or get entertainment through game live broadcasts. As a result, a large number of game anchors have been tapped and have a good fan base. Fourth, diversified live broadcasting. Diversified live broadcasts involve diverse live content such as conferences, competitions, and concerts [10]. People use mobile phones or computers and other terminals to watch diversified live broadcasts to meet their needs for diversified content. With the rapid development of the live broadcast industry, the value of diverse live broadcasts will be enhanced [11].

\section{Consumer purchasing decision theory}

Consumer decision-making theory is defined by Lei Xia (2017) as a process in which consumers carefully evaluate the attributes of a product, brand or service, make choices, and purchase products that meet a specific need. Most articles also quote this definition. In 1930, research on consumer purchasing decisions had already been carried out. According to Wang Dongshan (2017), consumer purchasing decision theory can be roughly divided into 'rational' decision theory, 'bounded rational' decision theory, prospect theory, preference construction theory, ecological rationality theory, and dual system theory [12].

First, it is the proposal of rational decision theory. Nobel Laureate Samuelson (PA Samuelson) proposed in his earliest paper "On the Pure Theory of Consumer Behavior" that the consumer demand curve can be derived from the preferences "shown" by market purchases. There is no need to resort to marginal utility theory or indifference curves. The theory of consumer purchase decision is gradually developed based on the soil of economics. This theory believes that in the choice of two commodities, consumers tend to follow two assumptions: one is that consumers are more inclined to choose products with greater utility, and the other is that consumers' decisions are rational. The interpretation of reason is that consumers can clearly measure and understand the true utility of commodities [13]. Expected Utility Theory (EU Theory) comes from "Game Theory and Economic Behavior" co-written by Johnvon Neumann \& Oskar Morgenstern (2012). Which introduces the expected utility theory. Expected utility refers to the weighted average of the utility of multiple results that the customer may get under uncertain conditions. From this, the expected utility theory has concluded that if the consumer's purchase decisionmaking process conforms to the utility axiom, then it must choose the product with the largest expected utility. Deeper research has corrected the deficiencies of EU theory in the expected utility axiom. Savage (1954) proposed Subjective Expected Utility, the SEU theory. He used subjective probability instead of objective probability to improve EU's theoretical model. Based on this, the EU and SEU theories conclude that rational people make consumer purchase decisions under uncertain conditions, and come to a rational decision theory [14].

Second, the 'bounded rational' decision-making theory was put forward. After the rational decision theory was put forward, many psychologists and economists have carried out repeated and deeper research, and their research results show that the consumption hypothesis of "rational people" using expected utility theory is incomplete with actual consumer purchases. meets the. When further research is carried out, Lin Zhuang (2009) proposed that the expected utility theory does not consider factors such as the bounded rationality, certainty effect and preference inconsistency of decision makers in real life [15]. In the actual application process, consumers' needs, emotions, and perceptions Psychological factors such as knowledge, motivation, personality structure, cultural background, decision-making context, etc. all have a significant impact on the real decision-making process, which will cause the decision-making process to deviate from rational rules. After the EU and SEU theories were questioned, Simon (1995), the Nobel laureate in economics, put forward the theory of bounded rationality. That is, consumers cannot harvest all the effective product purchase information in their purchase behavior, and the ability to analyze and measure product purchase information is limited, which is not purely rational. At the same time, the influence and interference of external factors will also affect consumers' purchasing decisions [16]. 
Third, prospect theory. Psychologists Kahneman and Tversky (2011) put forward the prospect theory from the perspective of cognitive psychology. The main idea is that consumer decision-making is divided into two processes: editing and evaluation. The editing process uses coding, combination, segregation and cancellation to analyze the profit and loss of the product in order to narrow the scope. In the evaluation stage, the weighting function (WeightingFunction) and value function (ValueFunction) are used by consumers to analyze the overall price of commodities (OverallValue), so consumers tend to choose to buy commodities with large overall value. The weight function reflects the influence of the attributes of commodities on the value of commodities. According to Wang Dongshan (2017), the value function is a consumer's subjective judgment on the utility of the commodity based on the relative change in the attributes of the commodity, which directly describes the relationship between the commodity and the psychological satisfaction of consumers. In general, the concept of decision weight function enables consumers to get a deeper analysis of actual purchase behavior, that is, the value of attribute weight assigned by consumers to commodities will be ranked by comparing the pros and cons of different commodities [17].

Fourth, the theory of preference construction. This theory was put forward by Bettman J. R (1988), that is, consumers' purchasing decisions are not influenced by existing things, but based on consumers' psychological cognition and emotions, combined with external environmental cues. In consumer purchase choices, Battman believes that maximizing correct choice, minimizing cognitive effort, minimizing negative emotional experience, and minimizing the difficulty of judging the rationality of choice are the main factors for consumers to choose products based on environmental cues at the time of purchase. Influencing factors [18].

Fifth, the theory of ecological rationality. This theory was put forward by Gigerenzer's team. They pointed out that human decision-making behavior is obtained through the combination of long-term evolution and interactive learning in learning psychology. Similar to the theory of finite decision-making, it also uses consumers' cognition to explore uncertain environmental clues. The final result makes the combination of the produce consistency and adaptability, and influence consumer decision-making.

Sixth, dual system theory. The theory holds that in people's minds when making decisions, there are two parallel processes operating at the same time, intuitive and rational. Kahneman (2014) uses experiments to prove that people are more inclined to use intuition when making decisions, and this is the cause of decision errors. On the other hand, consumers will use rational process operations to change or further adjust the error decisions they make, but rational systems often cannot completely correct errors. This is the dual system theory of consumer decision-making.

\section{INDUSTRY ANALYSIS}

\section{A. Industry development history}

Since people entered the Internet age, human development seems to have pressed the fast forward button. The extensive use of the Internet in many fields allows people to cross time and space, and with the development of the Internet, e-commerce seems to be an inevitable result. On Double 11 in 2011, Taobao, as an ecommerce giant, shocked the world with its sales volume, and also let people see the prospects and energy of the ecommerce industry. With the vigorous development of the Internet and e-commerce in the past few years, the power of the Internet celebrity economy has been reflected and grown.

The development of the internet celebrity economy does not have to be traced back to the earliest internet celebrities, such as Guo Jingming, Han Han and other internet novel writers and bloggers. In fact, the integration of internet celebrities into commercial value probably started around 2010. When social software such as WeChat and Weibo became widespread, official accounts and Weibo content became a subject of widespread attention. The insertion of advertisements by some bloggers with high attention from Weibo big Vs and public accounts in their content is the manifestation of the commercial value of the earliest Internet celebrities. With the development of small videos such as Douyin, Internet celebrities have created special video content, attracting the attention and pursuit of countless fans, with papi sauce as the representative figures. Internet celebrities who have fans receive the advertisement and add products to the short video content. As a result, Internet celebrities have gradually become a team and professional. And mainstream e-commerce platforms such as Taobao have also seized this opportunity to professionalize online celebrities and attract customers and traffic in various ways through live broadcast. The leading effects of some live broadcast heads such as Li Jiaqi and Wei Ya have injected tremendous energy into the industry.

The development and emergence of the Internet celebrity economy is promoted by many factors. First of all, it is the development of big data and e-commerce. According to the big data survey conducted by the Boston Consulting Group and domestic companies, it is found that young people's consumption trend of domestic brands has been de-branded, indicating that brands are no longer influential. The dominant concept of consumption. The current products are designed through big data analysis. The effective big data processing order itself reduces the warehouse and wholesale stage. The reduction of the industrial chain represents a reduction in costs and greater profit margins. The shorter the industrial chain, the lower the cost and the higher the efficiency. In addition, the competition for products of the same type is fierce, and what really catches the eye is nothing but innovative selling points, prices below the market, or the influence of spokespersons, etc. While Internet celebrities share their lives on the Internet, different Internet celebrities have their own unique positioning, such as eating and broadcasting, dancing, beauty and makeup experts. The 
fans attracted by such different positioning points have a high degree of relevance to the potential consumer groups of the product. In other words, the fan groups corresponding to different types of Internet celebrities have a high degree of matching with the potential customers of the merchants. Therefore, the way that Internet celebrities bring goods allows e-commerce companies to promote product promotion with higher quality and high Utilization. Compared with the effect of putting high-cost advertisements on the big screen to spread the net, the online celebrity bringing goods is regarded by the merchants as a new method of accurate delivery.

\section{B. SWOT analysis}

Strengths

(1) More accurate commercial content delivery

For online celebrities to bring goods, both the merchant and the online celebrities will have a two-way selection process. Businesses will choose those Internet celebrities who can advertise that their product characteristics coincide with their fan groups and their target groups, and the Internet celebrities will also choose businesses that can highlight their positioning. In this way, advertising is more accurate.

(2) Solve potential brand pain points and network celebrity supply chain issues

For mature brands, the one-stop production process from factory to sales is mature. What it lacks is platform and traffic. And what an online celebrity with goods needs is a mature supply chain that can fully meet customer needs. The combination of the two can complement each other and complement each other. The mature supply chain provides a comprehensive guarantee for the online celebrities to bring the goods, and the online celebrities live broadcast the goods with the help of platform technology and traffic to bring more exposure to the brand factories Publicity, especially for those new products that have just entered the market, is more effective.

Weaknesses

(1) Legal risks

Live delivery of goods is legally equivalent to daily advertising. The host is responsible for every word spoken in the live broadcast room. Any behavior that misleads consumers may be regarded as false advertising to deceive consumers., This is harmful to the platform, Internet celebrity anchors, consumers, and merchants. At the moment, Internet celebrities are not employees of the brand, and their descriptions of products are more or less inaccurate, which can easily mislead consumers.

(2) Vicious competition between internet celebrities and brand owners or other internet celebrities

Online celebrities will not be limited to the products of one brand, and the brand will not only need one internet celebrity to bring goods. It is easy to cause missed opportunities and vicious competition. For example, for brands, different pricing strategies may be required at different times, and this will definitely give some Internet celebrity anchors lower or higher prices. This can easily lead to consumers' distrust of the higher- priced anchors and learn to compare prices. However, in the process of comparing prices or watching the competition between the anchors, it is easy to cause competition problems and communication problems between the anchor and the brand. This not only makes consumers question the credibility of the two parties.

Opportunities

(1) The development of the mode and strategy of online celebrities bringing goods

Internet celebrities have an extremely fast development trend of bringing goods. For more popular Internet celebrities, they need lower prices and high cost of bringing goods from brands because they are the guarantee of traffic. How to find a balance between this and a relatively sustainable development strategy requires brand owners to study. For example, at the introduction stage of the product life cycle, invest in highly popular Internet celebrities to start the product. At such a high initial stage, even if there may be a loss, in the future through continuous customer repurchase and other online celebrities to sell goods may be greatly improved Commodity sales. The purpose of the head anchor is to introduce the product into the public view. In the whole process, there are a variety of sales strategies worthy of development, and at the same time they can obtain greater discounts and a wider selection of objects for consumers.

(2) Enterprise leaders join the industry to give energy

When the entire physical market is greatly impacted, such as the 2020 epidemic, the advantages of Internet celebrities in bringing goods can be vividly reflected. Some people say that in 2020, the decline of the real economy is an inevitable result, but the Internet economy and the real economy are not a substitute for each other, but a huge opportunity for the Internet economy. Just as Luo Yonghao joined the industry of live streaming with 48 million views and 110 million sales in three hours, this is another powerful interface for the docking market in the face of the powerful impact of the epidemic. Gree Group Chairman Dong Mingzhu also said after the live broadcast achieved 310 million sales, he would seize the huge energy of the live broadcast, 'in the future, Gree live broadcast may become the norm. 'In this way, the professionalism and sustainable development capabilities of the live broadcast have been improved through the participation of corporate leaders.

Threats

(1) The financing difficulty is too high

Although the Internet celebrity economy has developed at a super-rapid speed, what is needed for a single enterprise is the ability to adapt to the quarterly update. The iteration of the product requires the introduction of funds. However, Internet celebrity companies lack the ability to resist risks from the point of view of banks or some investment institutions, and the technical difficulty required for the products of online celebrities to bring goods is generally not high, which makes it extremely Low sustainability.

(2) Internet celebrities bring goods products that lack innovation and product characteristics

Many products, driven by Internet celebrities and blessings of trends, can make people feel bright, but this 
low-end innovation is often based on plagiarism and imitation. For example, many milk tea shops have to imitate the new products of other milk tea shops and change a new name that suits their own shop name characteristics. The result of blindly following the trend is that there is no technical improvement and innovation.

Many products brought by Internet celebrities copied popular styles and did not have their own unique product characteristics. When consumers can find the same products with the slogan of 'unique style' but without changing the medicine, it is difficult for people to have a desire to consume.

\section{FACTOR ANALYSIS}

\section{A. Consumer decision theory model}

According to Fang Fang (2015), it can be known that managers with "bounded rationality" in the "bounded rationality" decision-making theory are the people we see in real life. They have made two fundamental changes to the assumption of "economic man". The first is that the "economic man" deals with everything in the "real world", while the "manager" deals with the world that he perceives in his mind; the second is that the "economic man" looks for optimal decisions, and the manager only looks for satisfactory decisions. In addition to the practical impossibility of seeking the best, it may also add to the computational burden (often unaffordable) for decision makers. And a bounded rationality theory not only simplifies the calculation, but also explains the inconsistent behavior of people's choice behavior.

According to the original normative decision-making theory, any decision from people is the result of an absolute and all-round objective and scientific physical analysis. For subjective changes, mutual influence, and intervention, there is not too much focus, and they are sometimes regarded as ineffective decision-making elements. Therefore, the higher the degree of rational decision-making, the more effective decision-making is. Obviously, this decision-making theory cannot be applied to the subject of online shopping. The bounded rational decision theory is very suitable. Many people think that irrationality contains a purely derogatory meaning. When it comes to it, they think of "overcoming" and "reducing. In fact, irrational, like rationality, has both positive and negative aspects. Irrational provides motivation and rationality controls the direction. They share the same Control people's mental activities to affect people's behavior.

\section{B. Related empirical case analysis}

In the field of online celebrities carrying goods, because the commodity information that consumers can access is only through the description of the narrator and the simple perception in the live broadcast, strategies that affect subjective decision-making are often applied. For example, Douyin is the second largest live streaming window in the Chinese market. As an explosive application with extremely high traffic and daily active users, Douyin is also second to none in its live-streaming window, and has a very high upward trend. What Douyin does is to use big data to analyze the subjective preferences of individual users in short videos, and integrate personal preference data through likes, frequency of attention, and viewing time. In this way, the Douyin platform will recommend products corresponding to potential consumer groups to users who meet the characteristics. Therefore, controlling the user's preferences promotes a good user experience, and such an attractive experience often brings the user to an appointment. This inspires users' curiosity and potential purchase possibilities for live streaming. Therefore, the Douyin platform understands that consumers are not robots that are coded through a certain program when making decisions, but have the perception of love, hatred, and hatred to make decisions. Therefore, Douyin accurately grasps the curiosity and interest of the individual. When users click into the live broadcast room of interest, people's perception of the product will be subconsciously improved due to the high degree of satisfaction with the entire use of Douyin. Facilitates purchasing decisions.

Another attribute of internet celebrities bringing goods the influence of internet celebrities has also been emphasized and expanded by Douyin. For a short video platform, it draws on Instagram's hot entry approach to make it more precise and quick to control user value and public opinion orientation. Therefore, the Douyin platform can completely analyze the comments and evaluations of certain Internet celebrities or celebrities, and select positive value-oriented idols or Internet celebrities that are popular with the public for live broadcast. In the end, users or fans are very likely to be influenced by the influence of Internet celebrities to understand the product and produce a positive evaluation of it, which stimulates the user's potential purchase decision. The celebrity effect often has a very strong social influence, especially for Internet celebrities with a large number of fans and high-quality social evaluations. Therefore, consumers are likely to associate the outstanding success characteristics of Internet celebrities with products. Eventually, Internet celebrities and celebrities who have been collected by Douyin and have a positive orientation in the eyes of the public will be invited as guests with the goods, which inspires subjective perceptions such as imitation and novelty by real humans, thereby facilitating purchase decisions.

\section{RESEARCH CONCLUSION}

\section{A. Research result of this article}

Internet celebrities bringing goods is a relatively new industry with development potential, especially in the post-epidemic era. Internet celebrities bringing goods will be promoted by more and more brands and capital. However, as an industry with a development history of only a decade or so, its industry norms and guidelines are largely lacking, and we can only find a few legal provisions to restrict it. As a sales model that is directly related to consumers, consumers, sellers and Internet 
celebrities should all be protected by corresponding laws. Despite the existence of irregular management, the intervention of the platform can make the three parties reach a certain degree of balance. Such a convenient, rapid, and precise sales model has attracted more and more consumers, merchants, Internet celebrities, and platforms to its huge potential and advantages. In the future, more and more large and small businesses will enter the field of online celebrities carrying goods, which may become a very important market component. For merchants, the strategy of grasping the psychology of consumer decision-making and measurement in the field of online celebrities carrying goods needs to continue to develop, and the decisions people make must be based on many factors. Therefore, as Internet celebrities and merchants, the skills and strategies of online platforms influencing consumer behavior require more research and experimentation. The marketing strategy in the field of Internet celebrities bringing goods will become the research target of many brands in the future.

\section{B. Decision suggestion}

For consumers, people should make it clear that it is not necessarily comprehensive and comprehensive to understand only through online product information. Before the promulgation of laws and regulations, the statements of Internet celebrities and businesses may be deceptive and inducing. Although limited rational consumer decision-making greatly affects consumer behavior, in order to protect their own consumer rights, consumers should be more rational and make decisions through a more comprehensive understanding of commodities.

For merchants and Internet celebrities, the accuracy, consistency, and authenticity of information are aspects that greatly affect consumer loyalty. Bringing goods by Internet celebrities is by no means a short-term marketing strategy, but a long-term marketing goal and direction. Therefore, for products and consumers, absolute authenticity must be guaranteed. And the way to watch live broadcast online is worthy of merchants to use many techniques that affect consumers' subjective products or brand perception to promote consumer decision-making and consumption behavior.

For the platform, the work of protecting the rights of both merchants and consumers and pushing the products demanded by consumers needs to continue to improve. Controlling user preferences requires meticulous and individualized recommendations to help both consumers and businesses achieve the desired results.

\section{REFERENCES}

1. Baidu Encyclopedia. Net Red. 2019-06-22

2. Bilingual Exchange: Influencer/Internet celebrity. Reference news, 2019-12-16

3. Internet celebrities. Xinhua Dictionary, 2014-06-29.

4. Don't let "net celebrities" bias social values. Qianlong.com, 2018-09-15

5. Tan Chang, Jia Hua, Du Gang, Jiang Dan. Analysis of the definition, characteristics, development history and business model of webcasting[J]. Modern Business, 2018(19): 165-168.

6. Lei Yuting. Classification and feature analysis of new media live video broadcast [J]. News Research Guide, 2017, 8(04): 288.

7. Lei Xia. Theoretical analysis of consumer purchase decision. 2017

8. Wang Dongshan. Review and Prospects of Consumers' Purchase Decision Theory[J]. Business Economics Research, 2017(21): 43-46

9. Samuelson P A. A Note on the Pure Theory of Consumer's Behavior[J]. Economica, 2012, 5(17)

10. Neumann J V, Morgenstern O. Theory of Games and Economic Behavior[M]. Princeton, NJ: Princeton University Press, 2012

11. Simon H A.A behavioral model of rational choice[J]. Quarterly Journal of Economics, 2011, 69(1)

12. Kahneman D, Tversky A. Prospect Theory. An Analysis of Decision Making Under Risk[J]. Econometrica, 2011, 47(2)

13. Tversky A, Kahneman D. Advances in prospect theory: Cumulative representation of uncertainty $[\mathrm{J}]$. Journal of Risk and Uncertainty, 2011, 5(4)

14. Bettman J R, Luce MF, Payne J W. Constructive Consumer Choice Processes[J]. Journal of Consumer Research, 2011, 25(3)

15. Goldstein D G, Gigerenzer G. Models of ecological rationality: the recognition heuristic[J]. Psychological Review, 2013, 109(1)

16. Kahneman D. Maps of Bounded Rationality: Psychology for Behavioral Economics[J]. American Economic Review, 2014, 93(5)

17. Munro A, Sugden R. On the theory of reference- dependent preference $[\mathrm{J}]$. Journal of Economic Behavior and Organization, 2014, 50(4)

18. Fang Fang. Viewing decision theory and its development from the perspective of rationality and bounded rationality [J]. Inquiry into Economic Issues, 2015 (08): 64-67 